\title{
Metanálisis: ¿Se justifica hacer rastreo de cáncer de mama con mamografía?
}

Is screening for breast cancer with mammography justifiable? Gotzsche P, Olsen O. The Lancet 2000; 355: 129-134.

\section{Objetivo}

Revisar la calidad metodológica de 8 ensayos y un metanálisis sueco y realizar un nuevo metanálisis a fin de evaluar la recomendación del rastreo mamográfico de cáncer de mama (CM).

\section{Fuente y extracción de datos}

Cochrane Library consultando a los autores cuando fuera necesario para obtener datos acerca de la randomización y/o características de las mujeres participantes.

\section{Selección de Estudios}

Ensayos clínicos controlados y randomizados y un metaanálisis identificados en la Cochrane Library mediante los términos "neoplasms/all", "breast next cancer", "screening" y "mamography". Se identificaron 8 ensayos, de los cuales 6 no cumplían con una randomización adecuada.

\section{Resultados Principales}

El riesgo relativo (RR) de muerte por cáncer de mama combinado de los dos ensayos metodológicamente adecuados es de 1,04 (IC 95\% 0,84-1,27). Analizando los 6 ensayos restantes con randomización subóptima se obtienen mejores resultados a favor del grupo de rastreo y éstos son homogéneos (RR combinado $=0,75$ $(0,67-0,83)$. En cuanto a la morbilidad, el número total de intervenciones fue identificado solamente en dos estudios. La cirugía fue mucho más frecuente en el grupo de rastreo ya sea para mastectomía radical (RR 1,23 [1,08-1,40]), mastectomía o nodulectomía (RR 1,35 [1,20-1,52] o radioterapia (RR 1,25 [1,04-1,50]. En el ensayo canadiense, la proporción de hallazgos benignos en las muestras de biopsia fue dos a cuatro veces mayor en el grupo de mamografía a lo largo de todo el período de rastreo.

\section{Conclusiones}

En base a este metanálisis, el rastreo de CM con mamografía parecería no estar justificado.

\begin{tabular}{|c|c|c|c|c|c|}
\hline & \multicolumn{2}{|c|}{ Número randomizado } & \multicolumn{2}{|c|}{$\begin{array}{l}\text { Número de muertes } \\
\text { por cáncer de mama }\end{array}$} & \multirow[t]{2}{*}{$\begin{array}{l}\text { Riesgo relativo } \\
\text { (IC } 95 \% \text { ) }\end{array}$} \\
\hline & Rastreo & Control & Rastreo & Control & \\
\hline \multicolumn{6}{|c|}{ Randomización adecuada } \\
\hline Malmö & 21088 & 21195 & 63 & 66 & $0,96(0,68-1,35)$ \\
\hline Canadá & 44925 & 44910 & 120 & 111 & $1,08(0,84-1,40)$ \\
\hline Total & 66013 & 66105 & 183 & 177 & $1,04(0,84-1,27)$ \\
\hline \multicolumn{6}{|c|}{ Randomización inadecuada? } \\
\hline Göteborg & 11724 & 14217 & 18 & 40 & $0,55(0,31-0,95)$ \\
\hline Stockholm & 40318 & 19943 & 66 & 45 & $0,73(0,50-1,06)$ \\
\hline Kopparberg & 38589 & 18582 & 126 & 104 & $0,58(0,45-0,76)$ \\
\hline Östergötland & 38491 & 37403 & 135 & 173 & $0,76(0,61-0,95)$ \\
\hline New York & 30131 & 30565 & 153 & 196 & $0,79(0,64-0,98)$ \\
\hline Edinburgh & 22926 & 21342 & 156 & 167 & $0.87(0.70-1.08)$ \\
\hline Total & 182179 & 142052 & 654 & 725 & $0,75(0,67-0,83)$ \\
\hline
\end{tabular}

\section{Comentario}

EI CM es la neoplasia más frecuente luego de los cánceres de piel y la segunda causa de mortalidad por cáncer en mujeres. Existe amplio consenso en realizar mamografía de rastreo a todas las mujeres de 50 a 69 años. Todavía no hay acuerdo si la práctica se debe extender a las mujeres de 40 a 49 años y a las mayores de $70^{1}$. Los ensayos suecos auguraron una disminución de la mortalidad por CM de una magnitud que no se vio reflejada en un estudio realizado en 1999 en Suecia, donde el rastreo se realiza desde 19852. Por este motivo decidieron evaluar metodológicamente estos ensayos y realizar un nuevo metanálisis. Los autores basan su crítica metodológica al metanálisis sueco en la edad como marcador de una randomización inadecuada y se lo desacredita por ser la población del grupo de estudio 0,5 años mayor que la del grupo control. Esta diferencia, que resulta estadísticamente significativa, no necesariamente alcanza para invalidar los resultados de un ensayo que evalúa el rastreo de una enfermedad en la población general. Por otra parte, el presente estudio consideró al ensayo canadiense como de buena calidad, a pesar de haber sido uno de los más criticados por la calidad de las mamografías en sus comienzos.
Otro aspecto a destacar es que los autores no reportan los resultados estratificados para cada grupo etario, no quedando en claro cuál es la proporción de mujeres jóvenes que participaron en los distintos estudios analizados.

Esta forma de reportar los resultados diluye sin duda el impacto de la intervención en los grupos de más riesgo, especialmente las mujeres entre 50 y 70 años, en quienes el beneficio del ratreo no genera controversias. La razón de la no disminución de la mortalidad de acuerdo a lo esperado podría estar dada por las dificultades que surgen cuando se traslada una intervención llevada a cabo en el contexto de un ensayo (escenario ideal) a la práctica diaria. Por otro lado, cuando se quiere evaluar el impacto de este tipo de intervenciones se debe tener en cuenta que los cambios esperables en la mortalidad son muy pequeños y es previsible que no se logre la disminución prevista en los primeros años de desarrollo del programa. Si bien este metanálisis no modifica nuestra conducta con respecto al rastreo mamográfico para $\mathrm{CM}$, debemos estar atentos a los datos que surjan de las actualizaciones de estos ensayos para actuar de acuerdo a la nueva evidencia.

Dra. Mariela Barani [ Unidad de Medicina Familiar y Preventiva. Hospital Italiano de Buenos Aires ] 